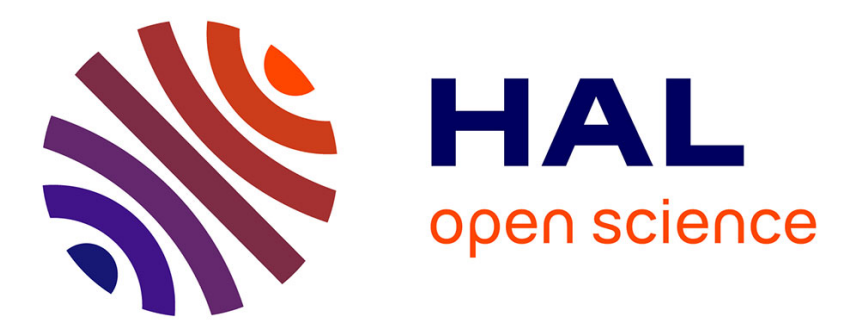

\title{
Flood lamination strategy based on a three-flood-diversion-area system management
}

Houda Nouasse, Philippe Charbonnaud, Pascale Chiron, Javier Murillo, Mario Morales, Pilar Garcia-Navarro, Guillermo Perez

\section{- To cite this version:}

Houda Nouasse, Philippe Charbonnaud, Pascale Chiron, Javier Murillo, Mario Morales, et al.. Flood lamination strategy based on a three-flood-diversion-area system management. 20th Mediterranean Conference on Control and Automation - IEEE MED 2012, Jul 2012, Barcelona, Spain. pp. 866-871. hal-00959277

\section{HAL Id: hal-00959277 https://hal.science/hal-00959277}

Submitted on 14 Mar 2014

HAL is a multi-disciplinary open access archive for the deposit and dissemination of scientific research documents, whether they are published or not. The documents may come from teaching and research institutions in France or abroad, or from public or private research centers.
L'archive ouverte pluridisciplinaire HAL, est destinée au dépôt et à la diffusion de documents scientifiques de niveau recherche, publiés ou non, émanant des établissements d'enseignement et de recherche français ou étrangers, des laboratoires publics ou privés. 


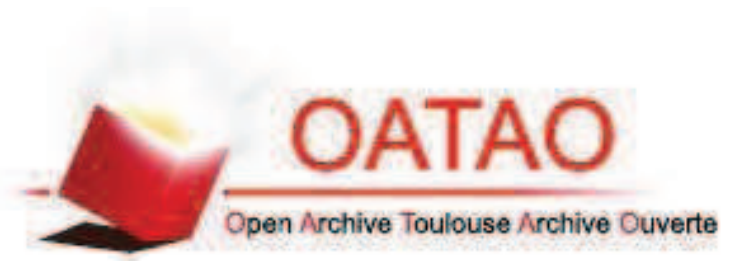

\section{Open Archive Toulouse Archive Ouverte (OATAO)}

OATAO is an open access repository that collects the work of Toulouse researchers and makes it freely available over the web where possible.

This is an author-deposited version published in: http://oatao.univ-toulouse.fr/ Eprints ID: 6624

To link to this article: DOI:10.1109/MED.2012.6265747

Official URL: http://ieeexplore.ieee.org/xpls/abs all.jsp?arnumber $=6265747 \& \operatorname{tag}=1$

\section{To cite this version:}

Nouasse, Houda and Charbonnaud, Philippe and Chiron, Pascale and Murillo, Javier and Morales, Mario and Garcia-Navarro, Pilar and Perez, Guillermo Flood lamination strategy based on a three-flood-diversion-area system management. (2012) In: 20th Mediterranean Conference on Control and Automation - IEEE MED 2012, 3-6 July 2012, Barcelona, Spain.

Any correspondence concerning this service should be sent to the repository administrator: staff-oatao@inp-toulouse.fr 


\title{
Flood lamination strategy based on a three-flood-diversion-area system management
}

\author{
H. Nouasse, P. Charbonnaud, P. Chiron, J. Murillo, M. Morales, P. Garcia-Navarro, G. Perez
}

\begin{abstract}
The flood lamination has for principal objective to maintain a downstream flow at a fixed lamination level. For this goal, it is necessary to proceed to the dimensioning of the river system capacity and to make sure of its management by taking into account socio-economic and environmental constraints. The use of flood diversion areas on a river has for main interest to protect inhabited downstream areas. In this paper, a flood lamination strategy aiming at deforming the wave of flood at the entrance of the zone to be protected is presented. A transportation network modeling and a flow optimization method are proposed. The flow optimization method, is based on the modeling of a Min-Cost-Max-flow problem with a linear programming formulation. The optimization algorithm used in this method is the interior-point algorithm which allows a relaxation of the solution of the problem and avoids some non feasibility cases due to the use of constraints based on real data. For a forecast horizon corresponding to the flood episode, the management method of the flood volumes is evaluated on a 2D simulator of a river equipped with a three-flood-diversionarea system. Performances show the effectiveness of the method and its ability to manage flood lamination with efficient water storage.
\end{abstract}

\section{INTRODUCTION}

Inland flood due to excessive precipitation and surface runoff remains the cause of extensive damage, loss of property and human injury worldwide. That is why a river system can be equipped with floodplains which must be defined according to its topography. The administrators of these systems are confronted with the necessity of making important decisions in an uncertain context. The integration of digital tools adapted to these crisis situations is relevant and necessary to improve decision-making [1], [2], [3]. However, the difficulty is linked to the choice of the optimization model which depends on device characteristics, on data availability, on objectives to be achieved and constraints to be satisfied. The management of the floods requires an increased reactivity with regard to the other planning-based managements [4]. The administrators have to elaborate their decision on foreseen scenarios for which the specific steps can be applied. In the literature, various approaches are proposed to deal with the flood management: linear programming [5], nonlinear programming [6], [7], multiobjective optimization [8] or genetic algorithms [9]. Among the resolution methods,

This work was supported by Conseil Régional de Midi-Pyrénées and Gobierno de Aragon (CTP project PREGO $n^{\circ} 08013953$ )

H. Nouasse, P. Charbonnaud, P. Chiron, are with University of Toulouse, INPT, ENIT, LGP, 65016 Tarbes, FRANCE houda.nouasse, philippe.charbonnaud, pascale.chirondenit.fr

P. Garcia-Navarro, M. Morales, J. Murillo are with Universidad Zaragoza, SPAIN. javier.murillo, mmorales, pigar@unizar.es

G. Perez is with CHE, Zaragoza, SPAIN. sadebro@ chebro.org there is some heuristics in particular the Ford-Fulkerson's Max-Flow algorithm [10], [11], [12]. The principle of these algorithms depends on the search of a spanning tree based on labeling nodes with minimal distance from the source to the sink (i.e., depth-first search, breadth-first search). In most of these algorithms the path search is a very important task for determining the optimal flow (flow decomposition theorem); leading in the proposed case to solutions which do not correspond to our management objectives. This point is illustrated on an example afterward.

The paper is organized as follows. Section II describes the problem statement of flood routing. The flood-diversionarea system is defined and the 2D modeling is introduced for the system dimensioning and the performance evaluation. Section III gives the main definitions of network flow modeling. A three-flood-diversion-area system modeling is detailed. Section IV proposes an algorithm implementing a flood lamination strategy integrating a nonlinear model of the gates. Section V presents an application to a threeflood-diversion-area system. The simulation results during a flooding period are displayed and a performance evaluation is discussed. Finally, the conclusion summarizes the interest of the flood lamination strategy combined to the 2D simulation.

\section{Problem Statement of Flood Routing}

The flood management can be studied on one hand by the dimensioning of floodplain areas and on the other hand by associating them a method of management during the flood episode. The river system planning is then realized according to socio-economic constraints and performances to be respected.

\section{A. Flood-diversion-area system}

A flood-diversion-area (FDA) system consists of floodplain areas equipped with controlled gates. The gate opening creates depression waves that interfere with the flood wave to reduce peak flood discharges. In the case of applying control over the gates, it could also be possible to have a control over the flood stage ( $h$ water depth) at certain points along the river where the flood reduction could be most beneficial. The roles of floodplain storage capacity and location, flood duration and flood peak discharge as well as gate operation is important to be evaluated.

\section{B. 2D Shallow water unsteady flow model}

The water flow under shallow conditions can be formulated by means of the depth averaged set of equations expressing water volume conservation and water momentum 
conservation. That system of partial differential equations will be formulated here in a conservative form as follows [13], [14]:

$$
\frac{\partial \mathbf{U}}{\partial t}+\frac{\partial \mathbf{F}(\mathbf{U})}{\partial x}+\frac{\partial \mathbf{G}(\mathbf{U})}{\partial y}=\mathbf{S}(\mathbf{U}, x, y)
$$

where $\mathbf{U}=\left(h, q_{x}, q_{y}\right)^{T}$ is a conserved variable and $h$ the water depth, $q_{x}=u h$ and $q_{y}=v h$ with $(u, v)$ the depth averaged components of the velocity vector $\mathbf{u}$ along $(x, y)$ coordinates. The fluxes of these variables are given by:

$$
\begin{aligned}
& \mathbf{F}=\left(q_{x}, \frac{q_{x}^{2}}{h}+\frac{1}{2} g h^{2}, \frac{q_{x} q_{y}}{h}\right)^{T}, \\
& \mathbf{G}=\left(q_{y}, \frac{q_{x} q_{y}}{h}, \frac{q_{y}^{2}}{h}+\frac{1}{2} g h^{2}\right)^{T},
\end{aligned}
$$

where $g$ is the acceleration of gravity.

The bed slope and friction are source terms of the momentum equations:

$$
\mathbf{S}=\left(0, g h\left(S_{o x}-S_{f x}\right), g h\left(S_{o y}-S_{f y}\right)\right)^{T}
$$

where the bed slopes of the bottom level $\mathrm{z}$ are

$$
S_{o x}=-\frac{\partial z}{\partial x}, \quad S_{o y}=-\frac{\partial z}{\partial y},
$$

and the friction losses are written in terms of the Manning's roughness coefficient $n$ :

$$
S_{f x}=\frac{n^{2} u \sqrt{u^{2}+v^{2}}}{h^{\frac{4}{3}}}, S_{f y}=\frac{n^{2} v \sqrt{u^{2}+v^{2}}}{h^{\frac{4}{3}}}
$$

This simulation framework was validated as shown in [15]. However, this model does not take into account the case where trees, rocks and floating objects are present in the river.

\section{C. $2 D$ modeling for the system dimensioning}

1) Benchmark: A simplified example of a river was defined as a benchmark. A river reach provided with three lateral floodplain areas is assumed. The river cross section is depicted in Figure 1. The river and the floodplains are separated by levees everywhere except at certain points where they are connected through a gate. These vertical levees are high enough for avoiding overflow. The study is based on a finite volume unsteady $2 \mathrm{D}$ shallow water flow simulation model (see section II-B). The computational

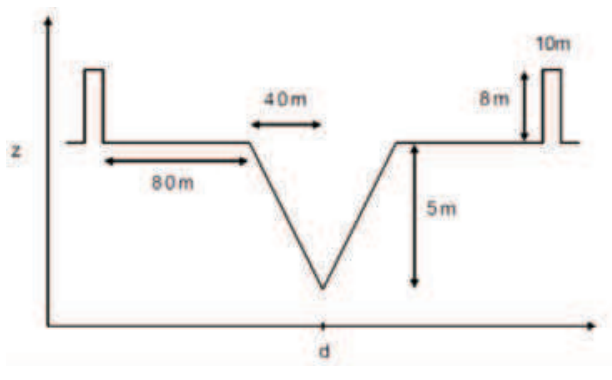

Fig. 1. River cross section

mesh is made of unstructured triangles. Nodes have been labeled defining the river longitudinal line, the river banks and the levee lines. the grid has 9484 nodes and 18812 cells and can be observed in Figure 2.

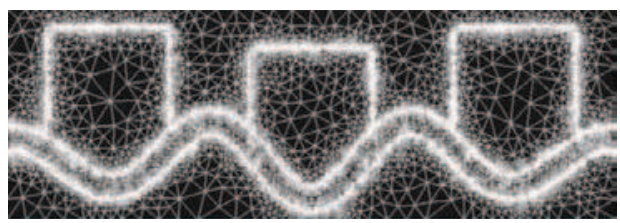

Fig. 2. Benchmark mesh

2) FDAs dimensioning : As a first step, the dimensioning of the FDAs was achieved. An important stake addressed in this modeling was to make it possible to show the influence of the topography on the performance of the flood lamination strategy. For carrying out digital simulations, boundary condition at the beginning of the river bed is given as an input hydrograph, which is Gaussian in the case study. Considering the Gaussian hydrograph as input denoted $Q_{\text {input }}(t)$ of the flood 2D-simulation. When gates are always open $(8 \mathrm{~m})$ the flow-rate output $Q_{\text {output }}(t)$ shows the wave deformation. Both flow-rates are displayed in Figure 3. The digital results

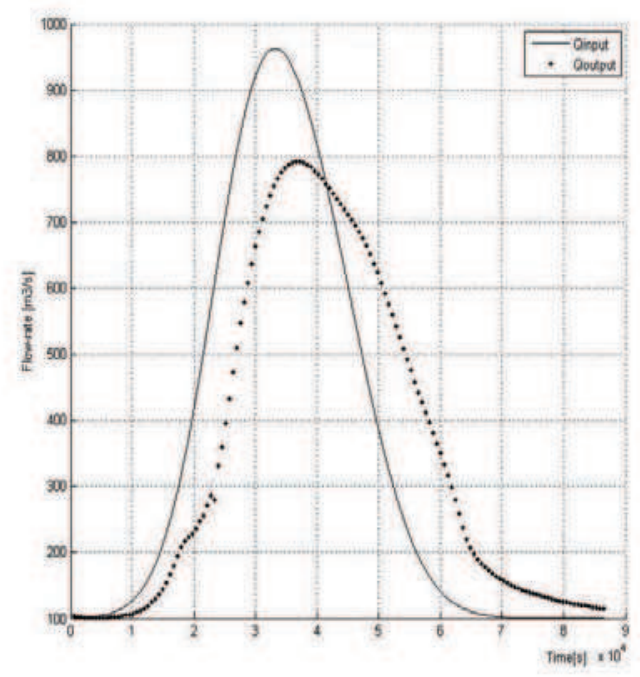

Fig. 3. $Q_{\text {input }}-Q_{\text {output }}$ of the benchmark with open gates

shown in Figure 4, demonstrate that the size of every FDA is adapted to the flood scenario.

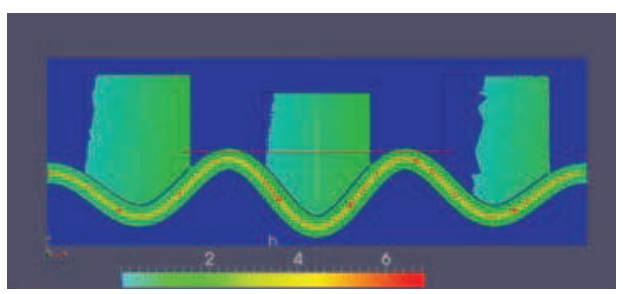

Fig. 4. Flood 2D simulation with open gates

\section{Objectives and performances}

The objectives are to laminate the flood at a given value denoted $Q_{\text {lam }}$ which corresponds to the lamination flowrate chosen by the river system manager. Qlam must be considered as a hydraulic set point over the foreseen horizon 
$H_{f}$ corresponding to a flood episode. During the lamination the flow-rate must be lower than $Q_{\max }$ defining the flowrate over which the water cross through the levees. At the opposite, an ecological flow-rate $Q_{e c o}$ has to be maintained at the outlet of the river.

Several indicators were proposed for evaluating the strategy efficiency. Firstly, the lamination rate $L R$ is expressed by:

$$
L R=\frac{Q_{P_{f}}}{Q_{\text {lam }}},
$$

where $Q_{P_{f}}$ is the effective lamination flow-rate computed for the period $P_{f}=t_{f_{2}}-t_{f_{1}}$ expressed by:

$$
Q_{P_{f}}=\frac{T_{c}}{P_{f}} \sum_{t=t_{f_{1}}}^{t_{f_{2}}} Q_{\text {output }}(t),
$$

where $t_{f_{1}}$ and $t_{f_{2}}$ are identified from the intersection of the given $Q_{\text {lam }}$ with the $Q_{\text {output }}$ of the river system when the gates are closed, as depicted in Figure 5 for $Q_{\text {lam }}=$ $700 \mathrm{~m}^{3} / \mathrm{s}$. Secondly, the rate of filling is defined by:

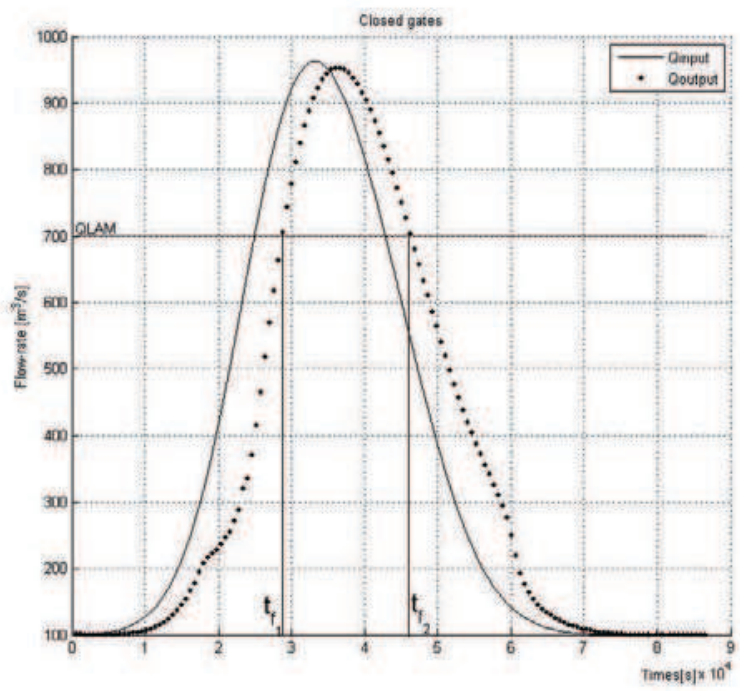

Fig. 5. $Q_{\text {input }}-Q_{\text {output }}$ of the benchmark with closed gates

$$
R F=\frac{V_{s}}{V_{o b j}},
$$

where $V_{s}$ is the sum of the volume stocked in the FDAs as expressed by:

$$
V_{s}=\sum_{i=1}^{3} V_{F D A_{i}}(h(t)) .
$$

$V_{F D A_{i}}$ is estimated according to the correspondence mapping between the water depth $(h)$ and the volume (see Figure 6). $V_{o b j}$ is approximated with the trapezoidal numerical integration of the flow-rate function above $Q_{l a m}$.

\section{NETWORK FLOW MODELING}

We consider networks [10], defined as connected ${ }^{1}$ directed graphs, which are acyclic, asymmetric ${ }^{2}$ and possessing a

\footnotetext{
${ }^{1} \forall i, j \in X$, it exists a path between $i$ and $j$.

${ }^{2} \forall i, j \in X,(i, j) \in \mathcal{A} \Rightarrow(j, i) \notin \mathcal{A}$.
}

source and a sink. $M=\left(m_{i j}\right)$, the node-arcs incidence matrix for graph $G=(X, \mathcal{A})$ where $X$ is the set of nodes and $\mathcal{A}$ is the set of arcs. Each node $i \in X$ corresponds to a row of $M$, and the column corresponds to an $\operatorname{arc} a=(i, j) \in \mathcal{A}$. It has the following structure:

$$
\begin{aligned}
& m_{i a}=+1 \quad \text { if } k=i \\
& m_{j a}=-1 \quad \text { if } k=j \\
& m_{k a}=0 \quad \text { if } k \neq i, j
\end{aligned}
$$

\section{A. Network flow definitions}

A flow in a Network $G=(X, \mathcal{A})$ is a vector $\varphi \in \mathbb{R}^{n}$, $n \geq 1$ that verify:

- $\forall i, j \in\{1, \cdots, n\}, \varphi_{i j} \geq 0 \Leftrightarrow \varphi \geq 0$

- in every node $i \in X$, Kirchhoff's law is satisfied:

$$
\sum_{j} \varphi_{i j}=\sum_{j} \varphi_{j i}
$$

$\varphi_{i j}$ is the flow on arc $(i, j)$. This condition might be written in matrix notation as follow, for $i \in\{1, \cdots, n\}$ :

$$
\sum_{j=1}^{n} m_{i j} \times \varphi_{i j}=0 \Leftrightarrow M . \varphi=0
$$

A transportation network is a graph that associate for each $\operatorname{arc}(i, j) \in \mathcal{A}$ a capacity $c a p_{i j} \geq 0$ (and if necessary a cost $\left.c_{i j}\right)$. It is the maximum limit of a feasible flow on $(i, j)$. A flow is feasible if and only if:

$$
\forall i, j \in\{1, \cdots, n\}, \varphi_{i j} \leq \operatorname{cap}_{i j} \Leftrightarrow \varphi \leq \operatorname{cap} .
$$

Let us consider $\varphi$ feasible flow for $G$. Given a flow $\varphi$, the residual capacity, $r_{i j}$, of any $\operatorname{arc}(i, j) \in \mathcal{A}$ represents the maximum additional flow that can be sent from node $i$ to node $j$ using the arcs $(i, j)$ and $(j, i)$. The residual capacity has two components: $c a p_{i j}-\varphi_{i j}$, the unused capacity of $\operatorname{arc}(i, j)$, and the current flow $\varphi_{j i}$ on $\operatorname{arc}(j, i)$ which

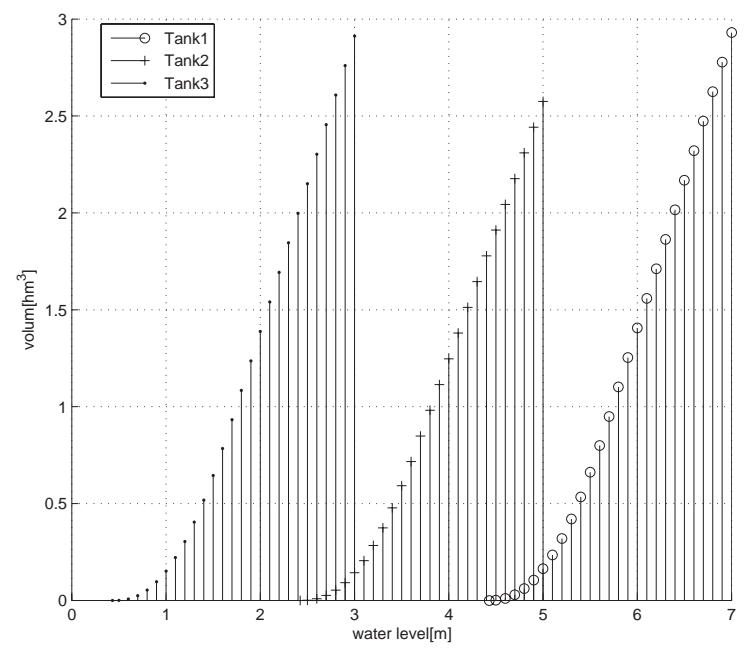

Fig. 6. Mapping tables 
can be canceled to increase flow to node $j$. Consequently, $r_{i j}=\operatorname{cap}_{i j}-\varphi_{i j}+\varphi_{j i}$. The network consisting of the arcs with positive residual capacities is called the residual network (with respect to the flow $\varphi$ ). We represent the residual network by $\bar{G}(\varphi)$.

\section{B. Three-flood-diversion-area system modeling}

For a three-flood-diversion-area system, the decision to open the gate depends on the flood, and supposes the control of the gate opening. This structure is described by a transportation network [10] which is static and without delays during the flow of water in the network. Gate modeling is detailed in section IV. The river system described previously is formalized by a directed graph $G=(X, \mathcal{A})$ (see Figure 7 ). The set of nodes $X$ consists of the source, three FDAs, the associated gates $(\mathrm{G} 1, \mathrm{G} 2, \mathrm{G} 3)$ and the sink. The flow vector $\varphi=\left[\varphi_{i j}\right]^{T} /\{i, j \in\{1, \cdots, \operatorname{card}(X)\}\}$ is carried by the $\operatorname{arcs}$ of $\mathcal{A}$ :

- $a_{12}$ : connecting the source (node with index 1) with G1 (node with index 2) represents the flow at $t=k T_{c}$, $k \in\{1,2, \ldots\}$ where $T_{c}$ is the control period in $H_{f}$.

- $a_{1 j},\{j \in\{3,5,7\}\}$ : connecting the source with the FDAs, representing the flow associated to the volume of water existing in FDAs at $t-1$.

- $a_{i j},\{(i, j) \in\{(2,3),(4,5),(6,7)\}\}$ : connecting each gate and its FDA, representing the flow crossing the gate towards the reservoir.

- $\left\{a_{12}, a_{24}, a_{46}, a_{68}\right\}$ : representing the flow in the river downstream the gate.

- $a_{i 8},\{i \in\{3,5,7\}\}$ : connecting the FDAs to the sink, it allows to consider the flow corresponding to the volume of water stored in the reservoir at the moment $t$, after each lamination.

We try to determine an optimal lamination flow which satisfies the physical constraints required by a flood scenario, the other constraints and the optimization method management parameters. In this case, the problem can be formulated as a Min-Cost-Max-Flow problem which minimizes a linear cost function subject to the constraints of flow conservation and minimal and maximal capacities [10], [11], [12]. Using a linear programming formulation we obtain:

$$
\text { Minimize } z=\sum_{i, j} c_{i j} \varphi_{i j}
$$

subject to

$$
\begin{gathered}
\sum_{j} \varphi_{i j}-\sum_{j} \varphi_{j i}=s_{i} \quad \forall i \in X \\
l b_{i j} \leq \varphi_{i j} \leq u b_{i j} \quad \forall(i, j) \in \mathcal{A} \\
\varphi_{i j} \geq 0 \quad \forall(i, j) \in \mathcal{A}
\end{gathered}
$$

$c=\left(c_{i j} \mid i, j \in X\right)$ vector of cost coefficient

$s_{i}$ the supply of node $i$, as $\sum_{i=1}^{\operatorname{card}(X)} s_{i}=0$ $s_{i}= \begin{cases}Q_{\text {input }}+\operatorname{stock}(t-1) & \text { if } i \text { source node } \\ 0 & \text { if } i \text { circulation node } \\ -\left(Q_{\text {input }}+\operatorname{stock}(t-1)\right) & \text { if } i \text { sink node }\end{cases}$

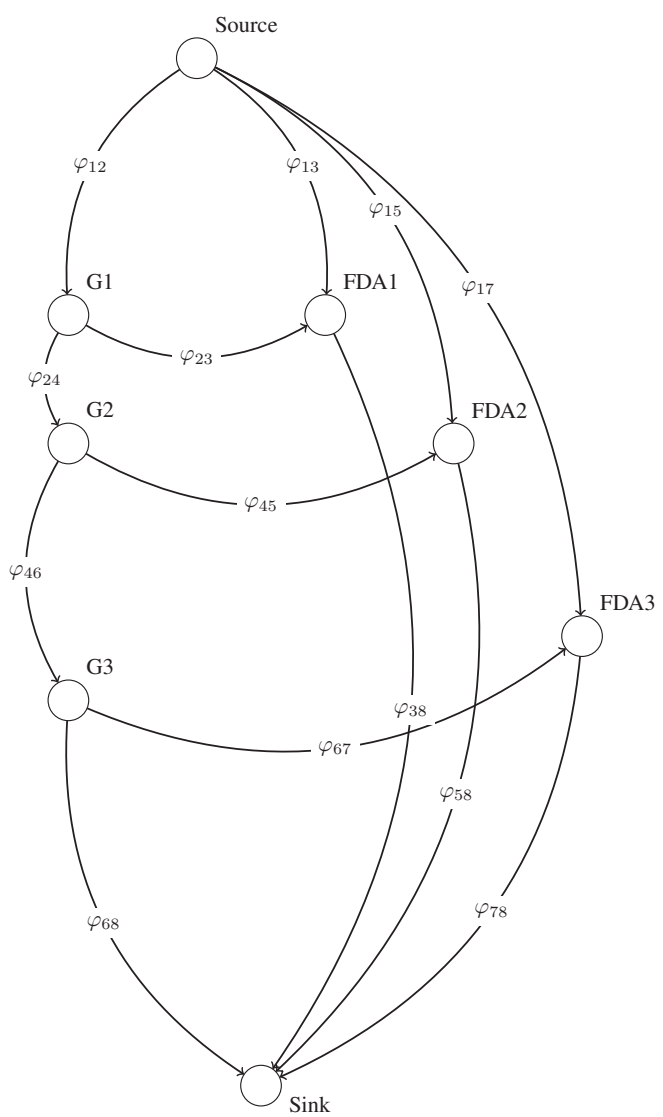

Fig. 7. Transportation network representing a 3 FDAs model

$\left[l b_{i j}, u b_{i j}\right]$ the feasible flow range of arc $(i, j)$ stock $(t-1)$ is the flow corresponding to the volume in FDAs at $(t-1)$

We assume that minimizing the FDAs gate solicitation for laminating the floods induce to reduce the management cost. Therefore, we propose the following objective function $z=$ $\varphi_{23}+\varphi_{45}+\varphi_{67}$ with cost coefficients $c_{23}=c_{45}=c_{67}=1$.

\section{Discussion on Max-Flow method}

Linear Programming formulation using interior-point method resolution [16], preferred to the use of classical resolution algorithm such as Ford-Fulkerson's algorithm in order to attain our management objectives. This is illustrated in the following example. The initial network in Figure 8(a) can represent a reach of a river system for the management of one FDA. We tried to maximize the physical flow in this case, by using Max-Flow formulation, solved by Ford-Fulkerson's algorithm. The solution is not unique and the algorithm gives three solutions depicted in Figures 8(b), 8(c) \& 8(d) among which two of them neglect the flow crossing the gate to the reservoir. These solutions do not satisfy our management objectives.

\section{Flood LAMination STRATEGy}

The flood lamination requires the storage of the water in excess. But there is a set of constraints about the filling of the floodplains mainly used for agricultural purposes. Two 


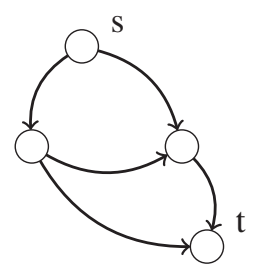

(a) Initial network

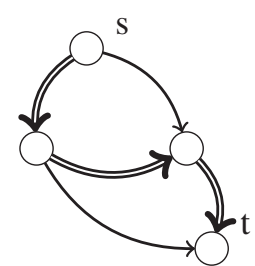

(b) Solution 1

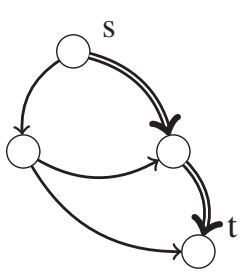

(c) Solution 2

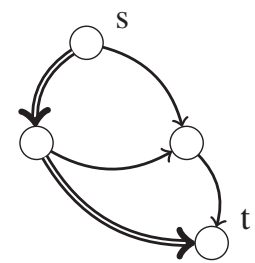

(d) Solution 3

Fig. 8. Example of possible solutions in a network on which was resolved a problem of Max-Flow with the algorithm of Ford-Fulkerson. (b), (c), (d) doubled arcs show the path of the optimal flow

main stages are proposed for achieving a flood lamination: firstly, the calculation of the optimal flow and secondly the calculation of the gate opening for every FDA.

\section{A. Gate modeling}

The calculation of the gate opening for every FDA depends on hydraulic parameters such as the flow-rate $Q$, the water levels meaused foreward and backward $d_{1}$ and $d_{2}$, the water heights measured with regard to the river bed $z_{1}$ and $z_{2}$, the gate width $L_{G}$ and the hydraulic constants $K_{1}$ and $K_{2}$. (see Figure 9).

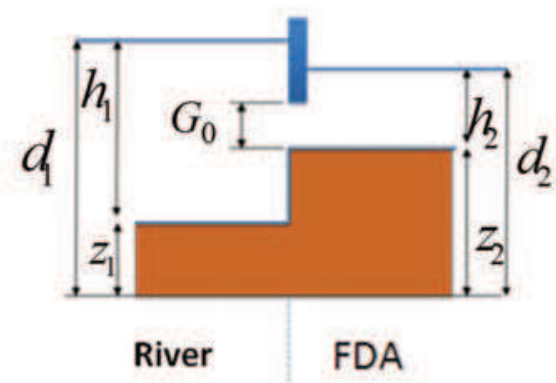

Fig. 9. Gate structure

- if $z_{1}>z_{2}$ and $d_{2}-z_{1}>G_{0}$ then

$q= \begin{cases}G_{0} K_{1}\left(d_{2}-d_{1}\right)^{\frac{1}{2}} & \text { if } d_{1}-z_{1}>G_{0} \\ G_{0} K_{2}\left(d_{2}-z_{1}\right)^{\frac{1}{2}} & \text { if } d_{1}-z_{1} \leq G_{0}\end{cases}$

- if $z_{1} \leq z_{2}$ and $d_{2}-z_{2}>G_{0}$ then $q= \begin{cases}G_{0} K_{1}\left(d_{2}-d_{1}\right)^{\frac{1}{2}} & \text { if } d_{1}-z_{2}>G_{0} \\ G_{0} K_{2}\left(d_{2}-z_{2}\right)^{\frac{1}{2}} & \text { if } d_{1}-z_{2} \leq G_{0}\end{cases}$

where $q=\frac{Q}{L_{G}}$.

\section{B. Flood lamination algorithm}

For a foreseen horizon $H_{f}$, sampled at the control period $T_{c}$, a management strategy given by algorithm 1 provides

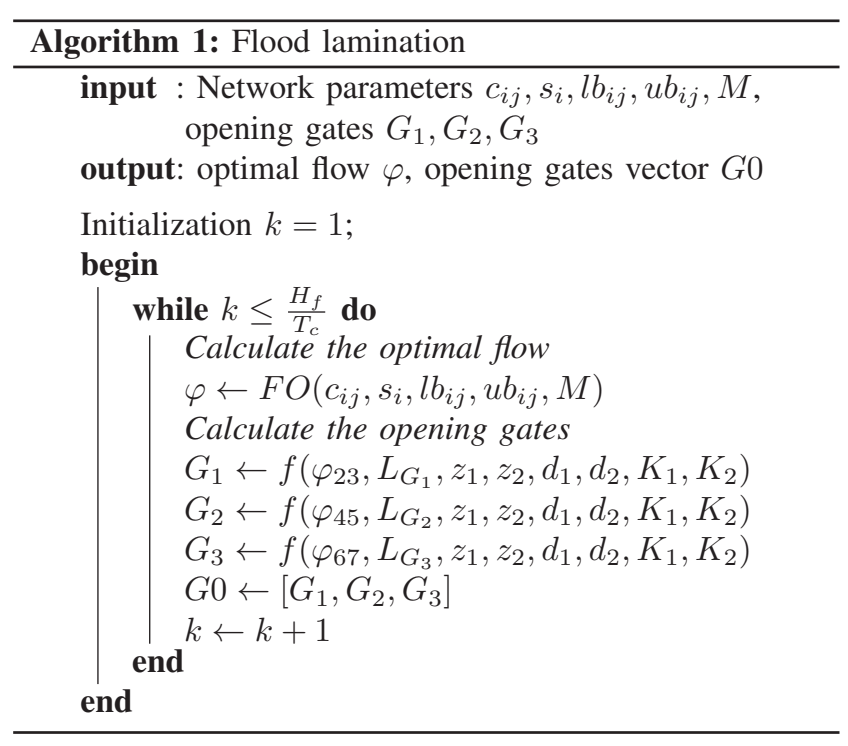

the way to calculate the next setpoints at every $T_{c}$.

In the algorithm 1, FO is the function implementing the transportation network optimization method described in paragraph III-B, $f$ is the function describing the opening gate relations detailed in paragraph IV-A. The gate opening is based both on Bernoulli's equation and mass balance in a hydraulic system for the case of a free flow open channel [17].

\section{APPLICATION TO A THREE-FLOOD-DIVERSION-AREA SYSTEM}

\section{A. Simulation during a flooding period}

By means of a 2D simulator of real time hydraulic flow (tool developed in Fortran), the flood management with a three-FDA structure was evaluated. We integrated the simulation tool and the flood lamination method (Matlab script). In Figure 10(a), $Q_{\text {input }}$ and $Q_{\text {output }}$ show the impact of the strategy. The error between the theoretical volume to laminate and the objective $Q_{\text {lam }}$ (see Figure 10(b)) is due to the nonlinear relation between the gate opening and the corresponding flow-rate which also depends on the water depths both in the river and the FDAs. In Figure 10(c), (d), and (e) the gate opening are displayed, showing the effectiveness of the lamination strategy. The 2D-simulation for $Q_{\text {lam }}=700 \mathrm{~m}^{3} / \mathrm{s}$ displayed in Figure 11 shows that the capacity of the FDAs is well dimensioned. There is no overflow.

\section{B. Performance evaluation}

We have proceeded to simulations of several scenarios. In Table I, the results of the performance evaluation are summarized. There is no significant differences for the lamination rate between the case where gates are always opened and the case where gates are controlled. However, the results on the rate of filling are in favor of the introduction of the flood control strategy. Because in this case, the quantity of water stocked in FDAs is lower than without flood regulation. In 

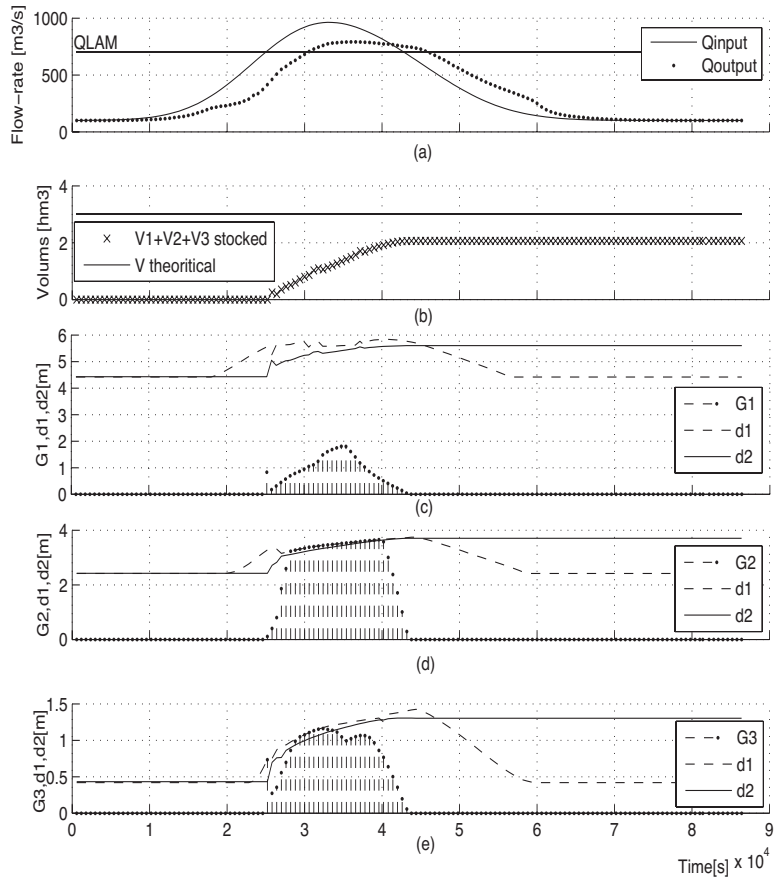

Fig. 10. Simualtion results for Qlam $=700 \mathrm{~m}^{3} / \mathrm{s}$

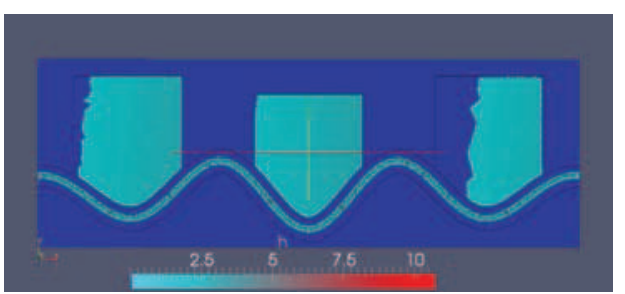

Fig. 11. 2D-simualtion results for Qlam=700 $\mathrm{m}^{3} / \mathrm{s}$

real cases multiple flood peaks can occur. It is very important to ensure a flood lamination without saving too much water in order to keep the capacity to stock a second flood. Moreover, less water during a short time may contribute to preserve the agricultural activities of the floodplains.

\begin{tabular}{l|l|l||l|l||l|l}
\hline Qlam & \multicolumn{2}{|c||}{$\mathbf{7 8 0}\left[\mathrm{m}^{3} / \mathrm{s}\right]$} & \multicolumn{2}{c||}{$\mathbf{7 5 0}\left[\mathrm{m}^{3} / \mathrm{s}\right]$} & \multicolumn{2}{c}{$\mathbf{7 0 0}\left[\mathrm{m}^{3} / \mathrm{s}\right]$} \\
\hline \hline Gates & Reg & Open & Reg & Open & Reg & Open \\
\hline LR\% & 106 & 102 & 108 & 104 & 111 & 110 \\
\hline RF\% & 95.4 & 137.5 & 77.84 & 108.8 & 68.9 & 78.5 \\
\hline
\end{tabular}

TABLE I

PERFORMANCES SCENARIO 2.3

\section{CONCLUSION}

A flood lamination strategy was presented to control a river system equipped with flood diversion areas. The strategy is based on a network flow modeling and guarantee the proposed performances. It's effectiveness was shown on a three-flood-diversion-area system. The $2 \mathrm{D}$-simulator is a useful tool for the dimensioning and the validation of the strategy for numerous scenarios. These performances can be improved by taking into account the time delay in the network flow modeling. Beyond a quantitative flood management an important problem to address is the quality of water in the river and in the FDAs. Future work and application will address both time delay modeling and water quality management. Finally, qualitative and quantitative management will be combined to control floods in presence of a pollutant.

\section{REFERENCES}

[1] C. Cheng and K. W. Chau, "Fuzzy iteration methodology for reservoir flood control operation," Journal Of The American Water Resources Association, vol. 37, no. 5, pp. 1381-1388, October 2001.

[2] D. R. Kracman, D. C. McKinney, D. W. Watkins Jr., and L. S. Lasdon, "Stochastic optimization of the highland lakes system in texas," Journal of Water Resources Planning and Management, vol. 132, no. 2, pp. 62-70, 2006

[3] X. J. Wang, R. H. Zhao, and Y. W. Hao, "Flood control operations based on the theory of variable fuzzy sets," Water Resour Manage, vol. 25, pp. 777-792, January 2011.

[4] C.-C. Wei and N.-S. Hsu, "Multi reservoir real-time operations for flood control using balanced water level index method," Journal of Environmental Management, vol. 88, pp. 1624-1639, 2008.

[5] J. T. Needham, D. W. Watkins Jr., J. R. Lund, and S. K. Nanda, "Linear programming for flood control in the iowa and des moines rivers," Journal Of Water Resources Planning And Management, vol. 126, no. 3, pp. 118-127, May-June 2000.

[6] A. Bemporad, A. Casavola, and E. Mosca, "Nonlinear control of constrained linear systems via predictive reference management," IEEE Transactions On Automatic Control, vol. 42, no. 3, pp. 340349, March 1997.

[7] C. A. Floudas, A. Aggarwal, and A. R. Ciric, "Globlal optimum search for nonconvex NLP MINLP problems," Compurers them. Engng, vol. 13, no. 10, pp. 1117-1132, June 1989.

[8] G. Fu, "A fuzzy optimization method for multicriteria decision making: An application to reservoir flood control operation," Expert Systems with Applications, vol. 34, pp. 145-149, 2008.

[9] X. Cai, D. C. McKinney, and L. S. Lasdon, "solving non water management models using a combined genetic algorithm and linear programming approach," Advances in Water Resources, vol. 24, pp. 667-676, 2001.

[10] R. K. Ahuja, T. L. Magnanti, and J. B. Orlin, Network Flows: Theory, Algorithms, and Applications. Prentice Hall, 1993.

[11] D. P. Bertsekas, Linear Network Optimization. MIT, Press, 1991.

[12] M. Gondran and M. Minoux, Graphs and Algorithms, 1st ed., J. W. S. Ltd, Ed. Discrete Mathematics, 1984.

[13] J. Murillo, P. Garcia-Navarro, J. Burguete, and P. Brufau, "A conservative $2 \mathrm{D}$ model of inundation flow with solute transport over dry bed," International Journal for Numerical Methods in Fluids, vol. 52, no. 10, pp. 1059-1092, 2006.

[14] R. Leveque, Finite Volume Methods for Hyperbolic Problems. New York: Cambridge University, 2002.

[15] J. Murillo, P. Garcia-Navarro, J. Burguete, and P. Brufau, "The influence of source terms on stability, accuracy and conservation in twodimensional shallow flow simulation using triangular finite volumes," International Journal for Numerical Methods in Fluids, vol. 54, no. 5, pp. 543-590, 2007.

[16] S. Boyd, Convex optimization, 7th ed. New York: Cambridge University Press, 2009.

[17] M. Chaudhry, Open-channel flow. Englewood Cliffs, N.J: PrenticeHall Inc, 1993. 